\title{
Teatro y posdictadura: La Organización Negra y sus modos de intervenir el espacio público en clave performática
}

\author{
María Laura (Malala) González \\ Universidad de Buenos Aires \\ Instituto de Investigaciones Gino Germani \\ Consejo Nacional de Investigaciones Científicas y Técnicas
}

\section{INTRODUCCIÓN ${ }^{1}$}

En primer lugar debemos puntualizar el objeto de estudio de esta reflexión: La Organización Negra -que de aquí en adelante denominaremos LON-, grupo teatral argentino que se gestó en la ciudad de Buenos Aires dentro de la Escuela Nacional de Arte Dramático apenas recuperada la democracia, y que desplegó su arte entre 1984 y 1992. Podemos decir que sus performances urbanas tuvieron la particularidad de haber sido realizadas en ámbitos urbanos: la calle, espacios públicos, edificios públicos y hasta lograron accionar sobre un monumento de la ciudad, durante ocho años de trabajo consecutivos. En ese lapso hubo continuidades, rupturas y formas estéticas a partir de las cuales lograron concebir un lenguaje artístico propio. Así, el recorrido grupal -definido a partir de un posicionamiento inicial en la periferia y reubicándose, luego, en el centro del campo teatral de Buenos Aires-advierte variables en modos de producción,

${ }^{1}$ Este artículo debe ponerse en continuidad con lo desarrollado en GonZÁLEZ 2015b, en tanto reelabora gran parte de las hipótesis allí planteadas. 
circulación y consumo de sus obras, generando un movimiento centrípeto con el paso del tiempo. Y por lo cual, su praxis teatral -antecesora de otras compañías teatrales contemporáneas, tales como De la Guarda o Fuerza Bruta- no fue lineal ni monótona, sino todo lo contrario. Pareciera que la experimentación por el propio hacer les resultó disparadora constante en la de búsqueda por lo cambiante y provocador.

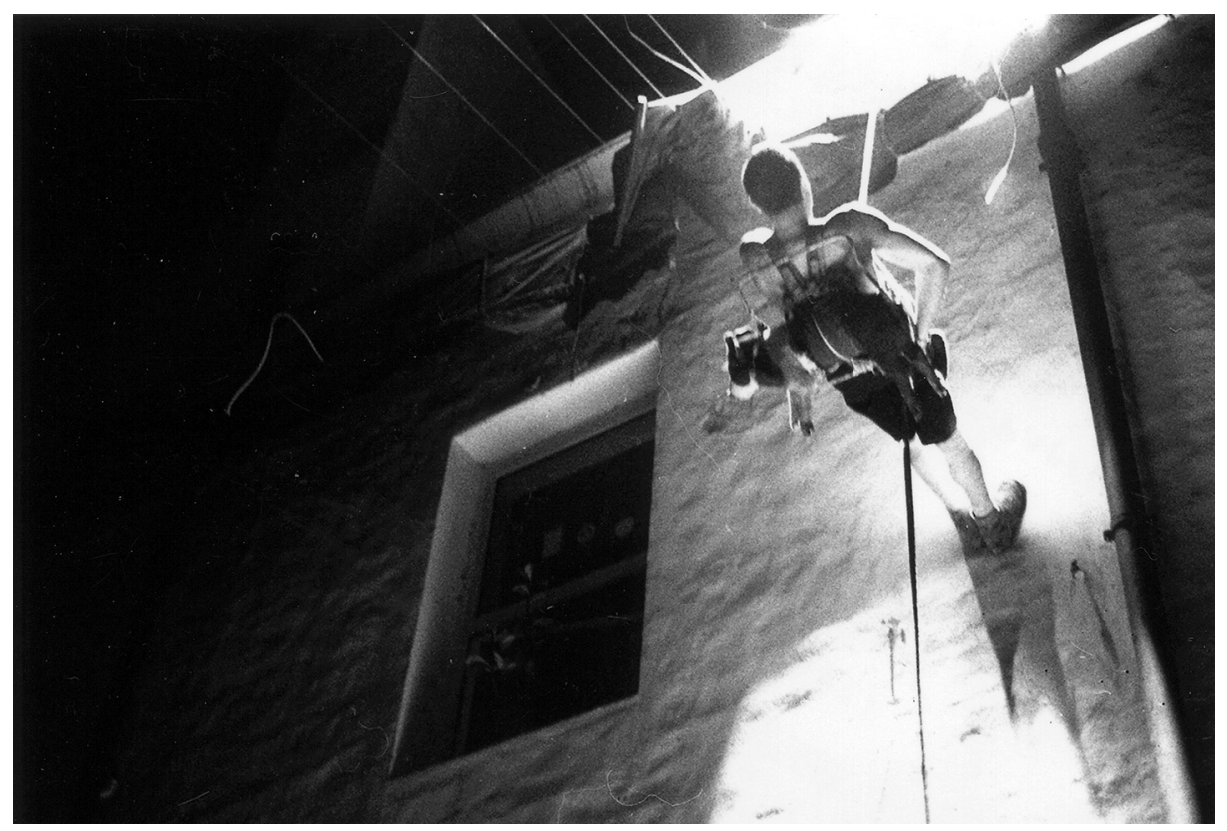

[Fig. 1. La Organización Negra, La Tirolesa. Centro Cultural Recoleta. 1988. Fotógrafo: Adrián Rocha Novoa.]

En esos modos de intervención urbana ligados al punk, al anarquismo, al sabor "aguafiesta" del retorno democrático, se puede leer cómo la articulación estético-política de sus prácticas siempre estuvo ligada al entorno urbano, y fue un vehículo común en toda su trayectoria. A partir de esto, nos proponemos focalizar la mirada sobre tres momentos puntuales o etapas de la agrupación: 1) los inicios vanguardistas dentro de la Escuela de Arte Dramático y luego dentro del espacio público, 2) los modos de legitimación dentro del campo teatral de la Posdictadura argentina, y 3 ) la llegada a una sala teatral convencional, que terminó con la disgregación de sus integrantes. Esto nos permitirá observar características de su poética y el contexto en el que tuvo lugar su acción, como así también los modos de ser pertenecientes a este grupo tan singular dentro de la Historia del Teatro argentino. 


\section{Posdictadura Como escenario de acción artístico-política}

Contextualmente, podemos decir que a mediados de 1983, el panorama socio-político de la Argentina vislumbraba el final inminente de la dictadura cívico militar iniciada el 24 de marzo de 1976. De esta manera, se inició un proceso de transición de la dictadura institucional de las Fuerzas Armadas hacia la tan ansiada democracia recuperada. Esto trajo consigo un período de "democratización por colapso" en el que el desenlace dictatorial fue posible, entre otros aspectos, gracias al inminente llamado a elecciones presidenciales. A partir del logro de esta instancia democrática de cambio en el régimen político de gran aceptación por parte de los ciudadanos-, en julio de ese año se llevaron a cabo dichas elecciones y el 10 de diciembre de 1983 asumió la presidencia el Dr. Raúl Alfonsín.

La apertura política trajo consigo un momento de cambios sociales, culturales y económicos. Se restituyeron, entre otros aspectos, el aparato estatal constitucional y representante de sus ciudadanos. Es decir, apareció otro régimen político de gobierno que instaló un proceso de nuevos modos de sociabilidad y de fortalecimiento de las instituciones públicas. Entre esos hábitos modificados, aconteció la posibilidad de manifestarse abierta y artísticamente desde lo colectivo, contrapuesto al canon de conductas que en el período precedente ligado al terrorismo de Estado, a la censura, la persecución y la desaparición de personas. La euforia, el entusiasmo y la efervescencia por desarrollar nuevas posibilidades de expresión signaron aquella conquista social y política, generando alegría en la ciudadanía y un clima de fiesta que floreció durante los primeros años de la transición, de la llamada Posdictadura Argentina. Así, después de varios años de represión, autoritarismo y terror - instaurados por el gobierno militar de facto--, los espacios de sociabilidad, la libertad de expresión, el libre tránsito por la calle, las manifestaciones artísticas, la justicia por los Derechos Humanos, entre muchos otros baluartes, volvieron a recuperarse.

\section{Candidaturas y Festival internacional:} la Posdictadura en la Escuela de Teatro

Corrían estos primeros años de Posdictadura cuando en la Escuela Nacional de Arte Dramático (ENAD) hubo un llamado a elecciones del Centro de Estudiantes. A partir de ello, algunos alumnos del primer año de la carrera de Actuación

\footnotetext{
${ }^{2}$ ANSALDi 2006: 29.
} 
se reunieron bajo un mismo propósito conformando una lista posible entre las candidatas: "la lista Negra" -que posteriormente sería renombrada como "La Negra" y luego como "La Organización Negra"-. Sin embargo, al proponerse para la candidatura su plataforma resultó algo alocada, en sus manifiestos aparecía un perfil anti-partidario e irónico que se alejaba de los demás partidos políticos candidatos. En este sentido, Manuel Hermelo, integrante de LON, recuerda que "éramos pocos los que no compartíamos las ideas de los otros. Entonces dijimos, armemos una lista: La Negra. . . . Así apareció el nombre. Se viene La Negra, y nadie sabía lo que era". ${ }^{3}$ Si bien no dieron a conocer a los demás estudiantes quiénes eran los que conformaban esa lista Negra, sí empezaron a instalarse como una opción colectiva posible, por fuera de los cánones de las agrupaciones tradicionales ${ }^{4}$. $\mathrm{Al}$ respecto, Fernando Dopazo, otro integrante de LON, recuerda:

El Partido Obrero pensaba por nosotros, Franja Morada pensaba por nosotros, La Federación Comunista pensaba por todos, todos querían pensar por nosotros. En términos de representación, la política quiere pensar por nosotros. Entonces nosotros lo que hicimos fue [armar] un gran programa, y sacamos un montón de votos. ¡Este es el comienzo!. ${ }^{5}$

Delineando un perfil nihilista, irónico y provocador -que escapaba a los cánones más convencionales - la lista Negra proponía hacer pensar al otro, descolocándolo de los lugares comunes o acostumbrados. Así LON comenzó a hacerse oír por los pasillos de la institución teatral proponiendo:

... Enad(es) [Escuelas Nacionales de Arte Dramático] en todas las cabezas de partido del país/ comedor escolar gratis/ asistencia bucodental en el establecimiento/ guardapolvo gris en las teóricas/ desparasitación de todos los gatos de la enad, sin excepción/ enanos de jardín sobre Aráoz/ agua caliente, jabón y esponjas en los baños/galpón para utilería/ consola de luces en la [sala] Constantín/ colección revista "libre" en biblioteca/ más fotos antiguas más/ ascensor hasta la terraza/ pelopincho en ídem/ más campeonatos de jámbol/etc. ${ }^{6}$

Con esta fuerte impronta de carácter anárquico-punk se conforma la agrupación. Y es en estos inicios grupales donde aparece la primera articulación entre arte y política manifiesta: fueron hijos del ejercicio democrático, gestado en función de profesar el derecho de volver a tener urnas, voz y voto, y de poder

3 Entrevista realizada por la autora de este artículo: GonZÁLEz 2008a.

${ }^{4}$ Vale mencionar que parte de ese anonimato colectivo inicial fue continuado durante toda su trayectoria, porque más allá de algunos programas de mano donde figuraban sus nombres, la denominación grupal era la que los identificaba como tal.

5 GonzÁlez 2008b.

${ }^{6}$ AA. VV. 1984: 6. 
elegir a sus representantes. Su libertad y participación en la candidatura fue posible gracias a la recuperación y apropiación de estas acciones de derechos civiles -abolidos durante los siete años de dictadura militar-. Esta transformación del aparato político gubernamental instaló cierto clima epocal de alegría y esperanza ciudadana; en el que la vida política trascendió y se desplegó por diferentes esferas sociales. En este sentido, las elecciones del centro estudiantil fueron un claro ejemplo de posibilidad de acción y participación política dentro de un ámbito artístico.

Simultáneamente a este primer año de cursada, se realizó en la capital de una provincia argentina, Córdoba, el Primer Festival Latinoamericano de Teatro $^{7}$. Ejemplo de apertura democrática por generar un intercambio propicio con artistas extranjeros, este evento no solo resultó significativo para los integrantes de LON -que viajaron especialmente en calidad de estudiantes espectadores-, sino también para el contexto nacional atravesado. La ocasión fomentó el diálogo con diferentes grupos y compañías teatrales. Según recuerda uno de los ideólogos de dicho festival, Rafael Reyeros, el evento "fue muy importante como opción política y social: Córdoba, a nivel democrático, se adelantó y abrió las puertas a manifestaciones artísticas de Latinoamérica y el mundo. Convocamos a todos, a todo el teatro del país y a toda la gente de acá. Todos teníamos que estar". 8

Si bien la programación contó con charlas, talleres, actividades y diecisiete puestas en escena ${ }^{9}$, el grupo destacado fue La Fura dels Baus con su espectáculo Accions. En efecto, la propuesta de la compañía teatral catalana resultó notoriamente diferente en relación con las demás, no solo por la intervención espacial ${ }^{10}$, sino también por el grado de provocación y de violencia instalados a partir de su performance en los espectadores asistentes ${ }^{11}$, entre los que se

${ }^{7}$ Iniciado el 18 de octubre de 1984, dirigido por Carlos Giménez, e ideado en conjunto con Rafael Reyeros, este evento cultural contó con varias sedes para su realización -la ciudad Capital, Río Ceballos, Carlos Paz, Alta Gracia y Río Tercero- logrando convocar una gran cantidad de público y teatristas de todo el país y del exterior.

8 OSPITAL 2009: 54.

9 Entre las puestas internacionales estuvieron: "Malayerba" de Ecuador, el teatro de la Universidad Nacional Autónoma de México (UNAM), La Fura dels Baus desde Barcelona, "Yuyaskani" de Perú, "Rajatabla" de Venezuela y Ellean Stewart del grupo "La Mamma" de Estados Unidos, más dos propuestas de teatro callejero nacional, Boca-River del grupo Dorrego y Juan Moreira del "Teatro de la Libertad" de Argentina. SeOAne 2011.

${ }^{10}$ Realizada en el patio de una escuela estatal de nivel primario.

${ }^{11}$ En Accions La Fura des Baus jugó con la implantación de acciones e imágenes visuales muy intensas. Violencia a partir del tránsito y composición de los cuerpos desnudos de los performers que se paseaban como zombies muy cerca y entre los espectadores. No había platea delimitada, sino música estridente envolvente y un guión de acción que impactó a todos los asistentes del evento. 
encontraban los integrantes de LON. Esta experiencia les demostró la posibilidad de pensar en un lenguaje teatral con otros parámetros, es decir, fuertemente vinculados con la transgresión espacial y la fricción con el espectador. Ambos elementos que LON perseguirá durante toda su trayectoria posterior, porque la proxemia de los cuerpos entre performers y espectadores a partir de una falta de delimitación entre platea y público fueron aspectos tenidos en cuenta a futuro. Así lo recuerda Manuel Hermelo: "ver a La Fura fue sentir, de golpe, que el cielo de la dramaturgia se te abría y que, por lo tanto, todo podía tener relación con otros intereses genuinos que existían en la época, con otros gustos, con nuevas expresiones". ${ }^{2}$

Al volver de la ciudad de Córdoba, las elecciones llegaron a su día de votación, y fue allí cuando LON logró obtener varios votos. Sin embargo, este logro no los motivó, y al año siguiente sus integrantes decidieron abandonar la formación actoral de dicha casa de estudios para ir en busca de otras expresiones no tan tradicionales. Y sin lograr concretar aquellas ideas explícitas en su plataforma electoral, dieron paso a un nuevo espacio, el "afuera" urbano, foco convocante de su interés artístico y sobre el cual se propusieron investigar. Voluntariamente estaban rechazando continuar en una institución de arte. Estaban eligiendo producir teatro a partir de y desde otros parámetros o registros menos formales. Para ello se replantearon otros modos de hacer contraponiéndose a la idea de espacios previamente delimitados - platea y escenario-, tal como habían visto y experimentado durante la realización de Accions, en Córdoba. Esto también los llevó a rechazar o desdeñar ciertas modalidades o paradigmas más convencionales de actuación. Es decir, se dieron cuenta que no querían contar una historia empleando un texto dramático previo, y que no querían abordar técnicas o procedimientos stanislavskianos como construir personajes, ensayarlos, sino que se encontraron frente a otra necesidad artística: la de ir en busca de otro tipo de teatro, de otra forma de teatralidad, más sorpresiva, más inesperada.

\section{LA CALLE COMO ESCENARIO POSIBLE}

En esta primera etapa grupal, trazaron un lazo entre el arte y la vida cotidiana, fruto del interés por explorar lo cotidiano. Junto con ello se puede vislumbrar la intención por generar un shock en la percepción del espectador -correspondientes con aquellos principios supremos de la intención artística de las vanguardias históricas de principios de siglo-, como un rasgo evidente que se

${ }^{12}$ Entrevista personal realizada por la autora de este artículo. GonZÁLEZ 2008a. 
manifiesta en la intervención de calles de la ciudad como escenario de acción. Allí, el objetivo grupal tuvo una premisa clara: "ganarle a las vidrieras". Esto significaba querer despertar la mirada de los transeúntes distraídos, generando una instancia poético-política diferente del orden cotidiano habitual dentro del propio espacio público cotidiano.

De algún modo el carácter democrático del período también se tradujo en esta elección espacial: salieron a la calle para despertarla de ese tiempo precedente en el que se había instalado en las calles el terror y la violencia. Salieron a expresarse teatralmente utilizando las formas propias que les brindaba este nuevo lugar urbano. Allí eligieron actuar sin platea previamente determinada, sin el cobro el de una entrada, sin escenario, sin un sistema de producción teatral capaz de contenerlos. Fueron en busca de otros espectadores, los transeúntes.

Durante el año 1985 LON realizó diferentes intervenciones de espacios públicos. Si bien de aquellas acciones poco registro queda, estos primeros pasos marcaron la búsqueda por un lenguaje propio a partir de generar una liminalidad entre ficción-realidad y planteando cruces difusos entre lo cotidiano y lo extracotidiano. Esto tuvo como resultado la experimentación de una forma de politicidad emergente, de hacer política con poco, de hacer arte desde otro lugar, salir a la calle no para protestar, sino para configurar formas poéticas de interpelación ciudadana. La enunciación performática de cuerpos sobre el asfalto -que no emitían palabras- marcaron otras formas de producir y consumir teatro en aquel entonces. Y fue esta periferia elegida por el grupo la que les posibilitó explorar otras posibilidades artísticas.

Algunas de estas performances realizadas en espacios públicos fueron: Los congelamientos, intervención de una esquina durante el tiempo de un semáforo, cuando algunos performers vestidos cotidianamente como los demás transeúntes, cruzaban la calle y -en un momento determinado- se detenían por unos segundos y se quedaban congelados, suspendidos en un tiempo otro, el de la ficción. Sin dar explicación de quiénes eran o porqué lo hacían, segundos después reanudaban su marcha hacia la otra vereda. Otra fue el Vomitazo, en el barrio de Retiro, que agregaba a aquel primer momento de detenimiento en el medio de la calle, la realización de un vómito colectivo por parte de todos los performers sobre el asfalto y sobre los parabrisas de los coches que esperaban detenidos el cambio de luz del semáforo en esa esquina elegida. Otra fue Los fusilamientos, también en el barrio de Retiro, que consistió en la simulación de un fusilamiento a partir del sonido de un disparo efectuado con pirotecnia. Al cruzar la calle, cuando el sonido ocurría, el grupo de performers abría sus sacos y dejaban ver sus camisas ensangrentadas para caer desplomados sobre el asfalto; sin embargo, luego de unos segundos se incorporaban y reanudaban su marcha 
hacia la otra vereda. Otra de ellas fue el Chanchazo - realizada en dos ocasiones en los barrios de Palermo y de Belgrano-, que recreó y simuló un salvataje y/o asistencia de urgencia médica por dos galerías comerciales, durante el cual varias enfermeras y enfermeros corrían entre la gente cargando y rodeando una camilla, que en vez de un paciente real contaba con un maniquí con cabeza de chancho. La última de estas intervenciones fue La Procesión o el paseo papal. Más extensa en tiempo de duración porque ya no se trató de intervenir solo una esquina, sino dos cuadras peatonales. Tuvo ensayos previos para calcular el recorrido/procesión de los performers comprometidos para la ocasión (aproximadamente diez). Esta acción se iniciaba con el depósito de varias bolsas de residuo sobre la peatonal Florida del microcentro porteño, en una "hora pico" minutos antes del cierre bancario. De ellas comenzaban a emerger desgarrando las bolsas, unas criaturas extrañas que abandonaban su posición fetal. Cada performer estaba caracterizado para cumplir un rol puntual dentro del esquema de acción. Había un Papa que iniciaba la marcha bendiciendo a la gente con talco y feligreses que lo seguían en esa especie de procesión urbana. Había mujeres -las lloronas-, tullidos, guardaespaldas que custodiaban al Papa, e incluso, entre estos performers, un asesino que lo acechaba. Todos los performers caminaban en forma de procesión entre los transeúntes de esa zona céntrica al ritmo de Carmina Burana, de Karl Orff, que sonaba en un radiograbador que cargaba otro performer haciendo movimientos de break dance. Cuando la procesión llegaba a la intersección con la avenida Córdoba, los esperaba una camioneta para retirarse del lugar. Antes de subir a ella hacían explotar una bomba de panfletos sobre la vereda que enunciaban lo siguiente:

Querido transeúnte como una pared descarada, como los instantes que siguen a un terremoto sorpresivo: LAARGENTINA SE CAE A CACHOS. Por este motivo es nuestro interés hacerte llegar estos consejos culinarios que, tal vez, te ayuden a sobrevivir en esta hecatombe que nos lleva a diosabedonde. Quizás hayas notado con frecuencia al untar una tostada con manteca, que esta suele romperse con facilidad. Hay una manera simple y generalmente desconocida que impide tal fractura: pon otra tostada debajo de la tostada que tú untas y verás cómo esta se mantiene intacta, crocante, deliciosa. Estas pequeñas instrucciones para sobrevivientes te las obsequiamos gratuitamente y desinteresadamente para que tu desayuno salga más rico en medio de la hecatombe. A propósito de gustos, querido transeúnte, te podemos decir algo al oído: NO NOS GUSTAS. La negra. 
Así, esta primera etapa de intervenciones se concretó sobre dos posibles márgenes respecto del campo $^{13}$ teatral de Buenos Aires: el socio-geográfico (dentro de la cuadrícula de calles de la ciudad, alejados de teatro convencionales) y el de valoración estética (por ser periféricos de las estéticas centrales al campo teatral). Incluso, se puede decir que el contexto cultural y el campo teatral porteño de aquellos años, junto con sus espacios públicos recreativos tales como parques o plazas, fueron también convertidos en escenario de acción por varios grupos teatrales callejeros. ${ }^{14}$ Sin embargo, el modo de proceder de LON fue muy distinto al de aquellos, cuyas intervenciones teatrales respondían a un tipo de teatro de calle más tradicional: como por ejemplo, se manifestaban convocando a la gente, delimitando el espacio de acción, llamando y convocando al público, avisando de la eminente ficción por acontecer.

Por el contrario, LON no buscaba generar una empatía en los transeúntes ni una función lúdica ni de entretenimiento. Sus acciones estaban guiadas para suscitarles asombro y sorpresa inesperada, generando discursos provocadores. No contaba con una narrativa de trama aristotélica en sus performances, ni buscaba incluir al público formando una ronda o delimitando el espacio escénico de los actores dentro del círculo logrado. LON concretó sus performances a partir de otra condición: tomar a la calle como espacio para modificar y modificarse en relación con sus hábitos y con la mirada acostumbrada a ver la ciudad siempre igual. Allí radicó su acción político-teatral. Si bien diferentes integrantes del grupo coinciden en haber tenido como referente a La Fura del Baus, como mencionábamos más arriba, algunos disienten en adjudicarse la influencia de performances de otros grupos tales como el Living Theatre. ${ }^{15}$

De todos modos, y más allá de las influencias tenidas en cuenta o no por el grupo, es posible articular el proceder inicial de LON con otros conceptos que articulan el arte y la ciudad. Por ejemplo, podríamos hablar de aquellas

${ }^{13}$ La noción de campo teatral -recurrentemente referida en este trabajo- se desprende del concepto elaborado por Pierre Bourdieu, el cual nos permite estudiar al artista y a su obra dentro de un espacio social complejo y autónomo, es decir, un sistema de relaciones constituido por la articulación e interacción de diferentes agentes (los propios artistas, críticos, editores, premios, instituciones, público, etc.), los cuales accionan sobre la producción, circulación y consumo de obras, determinando su dominación, valoración y legitimación dentro del mismo. BouRDIEU 1967.

${ }^{14}$ Entre los que cabe mencionar se encuentran: Teatro de la Libertad, Grupo Dorrego, Los Kelonios, Diablomundo, entre otros. Todos aquellos organizados en los que se llamó MOTEPO -Movimiento de Teatro Popular-, movimiento que logró tener una fuerte participación durante toda la transición democrática.

${ }^{15}$ Me refiero a que algunos de sus integrantes reconocen y otros no el haber leído una publicación de AA. VV. "Teatro 70" donde se enunciaban algunos manifiestos del grupo estadounidense y sus formas de accionar performáticamente sobre el espacio público, interrumpiendo el tiempo de un semáforo. 
primeras performances como obras de "arte contextual" 16 donde el espacio elegido (urbano en este caso) se volvió determinante para la realización de la performance, pensada para ser realizada allí y no en otro lugar, y en donde las coordenadas urbanas, sociales y políticas habrían sido alteradas a partir de la irrupción de la instancia ficcional y poética instalada. Asimismo, estas mismas performances urbanas pueden ser leídas bajo la noción de "arte público" ${ }^{17}$ por haber sido un arte realizado en el espacio público, y por haber pensado en su hacer a la propia ciudad como escenario, ya no como mero elemento espacial o contenedor sino como espacio de acción, de diálogo y de transformación política. El detener cuerpos en el espacio de tránsito, plantear otros ritmos del cotidiano habitual, generar imágenes de violencia sobre el asfalto, provocar a los automovilistas vomitando sobre su parabrisas, proponer un salvataje de urgencia ficticia, son prácticas estético-políticas que permiten ser pensadas en clave de arte de especificidad espacial. ${ }^{18}$ Específicamente, se trataría de prácticas donde la ciudad como soporte fue tematizada, generando imágenes de conflicto ya no consecuentes con la alegría y fiesta democráticas, sino con el terror instalado en sus calles en el tiempo precedente dictatorial. Este acto de descolocar al transeúnte de su continuum habitual, de romper con la mirada acostumbrada y de generar preguntas sobre lo que hacían, fue correlativo con lo realizado dentro del Conservatorio, cuando los demás estudiantes se preguntaban quiénes eran La Negra y cuán alocadas resultaban las ideas que proponían. Es decir, en el espacio público también instalaron la pregunta de "¿quiénes eran?” y “¿por qué y para qué hacían lo que hacían?”, en una correspondencia con sus prácticas iniciales.

En estos momentos iniciales, los modos de producción con los que contaban para intervenir las calles fueron emprendidos desde la autogestión. A los vestuarios cotidianos o prestados, le sumaron elementos de pirotecnia, y luego materiales descartables que emplearon para La Procesión. En estos momentos la circulación de sus performances estuvo ligada al orden cotidiano de esos espacios urbanos elegidos, sin anticipación o alerta previa de su acontecer teatral. Por lo tanto, el consumo de estas prácticas iniciales estuvo dirigido a los transeúntes desprevenidos que pasaban por casualidad por esa esquina o vereda. Esto se relaciona también con la falta de domesticación tecnológica de aquel entonces, puesto que en esos años no podían apelar a un registro posible de estas acciones como sí podría ocurrir en la actualidad. En este sentido, luego del rechazo por lo institucional y convencional del campo teatral argentino, aparece una experimentación de cercanía con la realidad que desemboca en los

\footnotetext{
16 PÉREZ RoYo 2008: 15.

17 DuQue 2005.

18 Blanco et al. 2001.
} 
"castrejos" (mezcla de calle y trabajo) o de "ejercicios" urbanos iniciales (como a ellos les gustaba llamarlos) cuya recepción resultaba mayoritariamente desorbitante e inesperada.

En resumen, estos primeros años de LON estuvieron atravesados por la experimentación. Fueron jóvenes que buscaban un modo (otro) de expresarse, corriéndose de lo teatral convencional, pero indagando en algunas de sus formas. Performáticamente la exploración del lenguaje escénico los encausó hacia la calle, hacia el espacio público periférico. Allí sus intervenciones urbanas -apoyadas en lo corporal- se proponían "parar el mundo" en plena hora pico. Eran los primeros años de la posdictadura cuando recién se habilitaba ese juego de miradas capaces de llamar la atención y ganarles a las vidrieras, repensando y restituyendo el vínculo con los otros. Estas escenas sorprendían, shockeaban y abrían preguntas ¿Quiénes eran ellos? ¿Por qué hacían lo que hacían? Un primer momento atravesado por la efervescencia democrática, las ganas de hacer y de decir, sin palabras, sino corporalmente sobre el asfalto.

\section{SEgUNDA ETAPA GRUPAL: EL RECONOCIMIENTO INSTITUCIONAL}

\section{UORC ENTRE LA DISCOTECA, LA UNIVERSIDAD Y UN FESTIVAL CULTURAL}

La década de los 80 avanzaba y dio lugar a la segunda etapa grupal que vino de la mano de un éxito suscitado por la performance UORC-teatro de operaciones, la cual realizaron durante dos años consecutivos, todos los días jueves en una discoteca del barrio de Constitución: Cemento. Allí, los jóvenes asiduos a la música rock hacían cola para verlos en aquella guarida cultural, en la que también iban para escuchar a sus bandas preferidas. Imágenes tan potentes como violentas eran parte de la acción performática. Imágenes en donde lo corporal aparecía como soporte de aquel "tren fantasmas para adultos", según calificaban el espectáculo las críticas periodísticas de la época. Decimos críticas porque justamente es en esta etapa cuando comienza el reconocimiento y la legitimación por parte del campo teatral-cultural, al tiempo que los catalogaban como grupo vanguardista de las nuevas tendencias contemporáneas.

Entonces, esta legitimidad fue propiciada por el éxito acontecido entre 1986 y 1987, cuando LON intervenía Cemento. En cuanto a esta discoteca, podemos decir que, junto con otros recintos se ubicaba en un espacio periférico al circuito teatral convencional, y fue parte de un conjunto de lugares alternativos que emergieron por diferentes barrios de Buenos Aires, principalmente 
a partir del advenimiento democrático ${ }^{19}$. Estos espacios -sótanos, locales, bares- resultaron claves para la manifestación de las nuevas tendencias artísticas -musicales y teatrales- de diferentes grupos emergente ${ }^{20}$ que fueron capaces de generar un panorama heterogéneo en la ciudad, compuesto de múltiples micropoéticas teatrales. ${ }^{21}$ En Cemento, LON logró consagrarse como un grupo vanguardista en relación con las nuevas tendencias teatrales que comenzaban a aparecer y a poblar la cartelera porteña de aquellos años. Aun cuando fuesen varios los grupos que transitaban esos mismos espacios periféricos durante las noches porteñas, estos se diferenciaban de LON por emplear otro tipo de técnicas, ligadas al humor, a la improvisación, al clown, a la poesía, e incluso por transitar otros formatos de sketch o de varieté.

En este sentido, podemos decir que fue la crítica periodística la que le asignó a LON esa reubicación dentro del campo teatral. A partir de su permanencia en cartel y éxito de convocatoria, fueron varios los periodistas que intrigados por lo que ocurría en Cemento semanalmente, fueron convocados a vivir la experiencia en primera persona. Desde ese momento, la crítica se percató de la existencia de LON (hasta entonces inadvertida) tratando de analizar y conceptualizar si lo que hacían era teatro o no. Tanto la provocación sobre el espectador, como la no delimitación del espacio escénico y la platea, junto con la falta de palabras que proponían las imágenes corporales construidas, fueron elementos procedimentales resaltados para notar lo novedoso que tenía esta propuesta escénica. Una de aquellas críticas decía:

El espectáculo de La Organización Negra, suerte de "tren fantasma para adultos", incorpora la violencia no solo como contenido, sino como forma que apunta a desacomodar a percepción del espectador. Sin palabras, pero ajustándose a un preciso texto dramático, los actores avanzan sobre el público, amenazándolo, forzando una redistribución de espacios en la que todos resultan comprometidos en lo que sucede. La fábula propone un universo gobernado por una represión robótica, máquinas implacables que torturan a sus antagonistas y engendran nuevos habitantes de ese sistema gobernado por la tecnología. La representación del mundo propuesta por La Organización Negra no contempla la piedad y su "teatro

19 Nos referimos, entre otros al Parakultural, Centro Cultural Ricardo Rojas, Bar Einstein, Taller y Medio Mundo Varieté.

${ }^{20}$ En material teatral, nos referimos al Clú del Claun, Las Bay-biscuit, el Teatro Malo (de Vivi Tellas), Las Gambas al ajillo, Los Melli, Los Macocos, Batato Barea, Alejandro Urdapilleta y Humberto Tortonese, La Banda de la Risa, el Teatrito y La Cuadrilla, entre tantos otros surgidos dentro de estos espacios. Y en materia musical, podríamos mencionar a Los redonditos de Ricota, Sumo, Soda Stereo, Los Twist, entre otros.

${ }^{21}$ DubatTi 2006. 
de operaciones" recrea la angustia de la vida cotidiana proyectándola en un porvenir de historieta posmoderna. ${ }^{22}$

En efecto, en esta performance $U O R C$ los performers no hablaban pero sí respetaban un guión de acciones, cual partitura. Corrían entre la gente (parada, sin platea) y luchaban entre sí según los momentos de acción bien pautados por la banda sonora que los guiaba. Recreaban una atmósfera posnuclear, de devastación, en la que la supervivencia de sus cuerpos se enunciaba como la única materialidad escénica necesaria. Por momentos los performers eran obreros, por momentos zombies corriendo entre el público, por momentos se volvían soldados o aliens que luchaban entre sí, rompiéndose tubos fluorescentes, en una pelea por la propia supervivencia.

Imágenes ligadas a una representación de la violencia, de lo violento, mediante un riesgo corporal proxémico con el público. Un collage de secuencias corporales que se volvía capaz de otorgar múltiples sensaciones en el público que gritaba, se asustaba, corría por todas partes de la discoteca. La idea era estimular al otro, hacerlo pensar, sacarlo de los lugares comunes fueron características que -trascendiendo la práctica política inicial-se trasladaron a la práctica teatral acuñada puertas adentro de la pista de baile.

Inicialmente, en UORC los modos de producción fueron similares a los de la primera etapa, salvo cuando comenzaron a repetir las funciones. Para ello necesitaron que la gran cantidad de materiales descartables - que destruían en escena- fueran repuestos función tras función. En esta etapa aparece la música de Gaby Kerpel como un sistema significante fundamental dentro del texto espectacular construido por LON. Allí, el ritmo de los sonidos estridentes marcaba el tempo de las acciones de cada escena recreada.

Respecto de la circulación que tuvo como obra, a partir de recomendación del boca en boca de los asistentes, UORC comenzó a hacerse conocida dentro del ambiente, incluso a partir de las críticas que fueron apareciendo. Por el tipo de espacio elegido, se podría decir que la convocatoria de público estuvo compartida entre habitués teatrales y asiduos de rock, ya que en varias funciones el espectáculo funcionó a modo de "teloneros" o soporte de bandas musicales que tocaban más entrada la noche en dicha discoteca.

Entonces, fue a partir de este reposicionamiento dentro del campo, lo que desembocó en dos intervenciones urbanas institucionales: el patio de la Facultad de Ingeniería de la Universidad de Buenos Aires y el patio del Centro Cultural de la Ciudad (actual Centro Cultural Recoleta). Dentro de estos edificios institucionales municipales el shock buscado inicialmente por LON, se trasladó voluntariamente a los espectadores, quienes advertían que la obra de teatro/

22 Castro, Warley 1987. 
performance tenía el plus de desconcertar con la propuesta a quienes asistieran. Porque era teatro, pero tenía algo más.

\section{Otro festival: La Tirolesa en el Centro Cultural Recoleta}

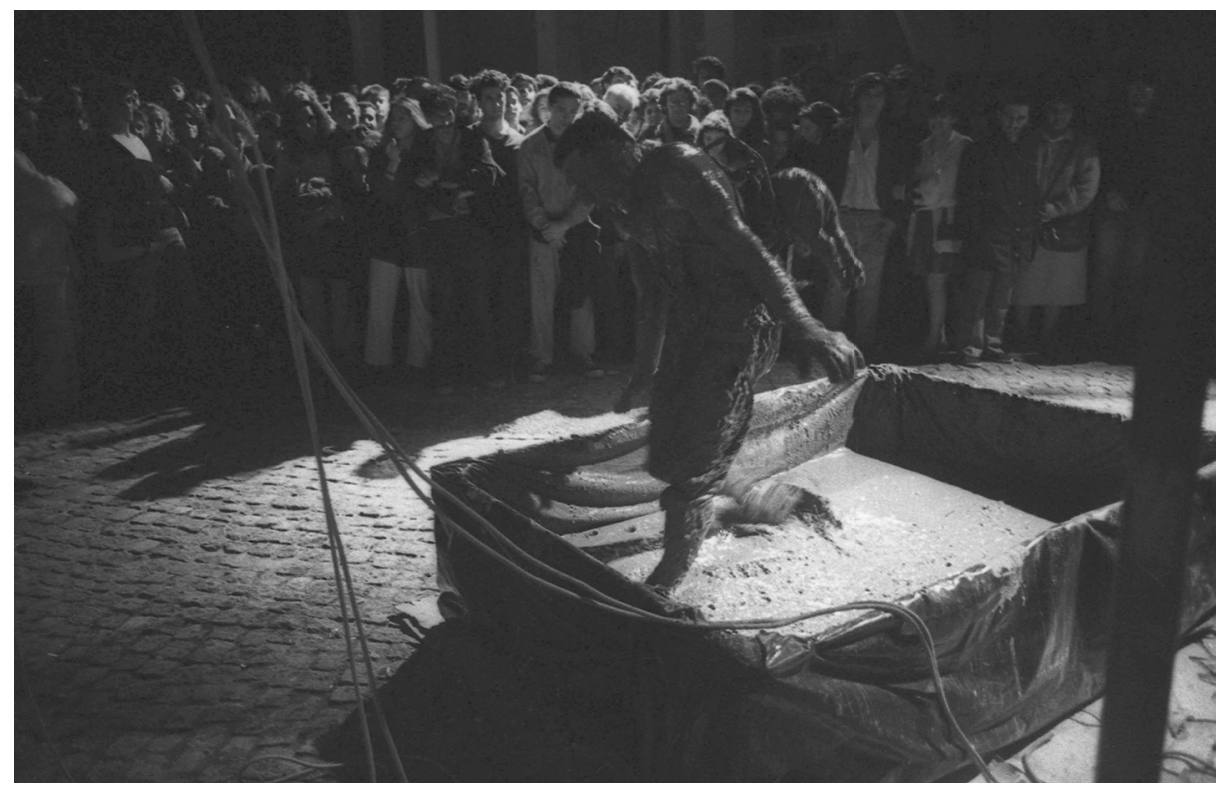

[Fig. 2. La Organización Negra, La Tirolesa. Centro Cultural Recoleta. 1988. Fotógrafo: Adrián Rocha Novoa.]

Decíamos que luego del reconocimiento otorgado por la crítica local respecto de $U O R C$, el grupo fue convocado oficialmente para participar en dos programaciones institucionales: el Programa Cultural en Universidades (Facultad de Ingeniería de la Universidad de Buenos Aires), a fines de 1987; y el Festival Nuevas Tendencias II (Centro Cultural Ciudad de Buenos Aires) durante 1988. En el primero repitieron - para los jóvenes estudiantes de dicha Facultad- la performance UORC; y en el segundo realizaron La Tirolesa, en el patio de dicho centro cultural. Con ambas invitaciones el grupo estableció un nuevo vínculo político institucional y cobró un caché por acceder a presentarse en ambas programaciones, dependiente, en última instancia, de fondos públicos municipales. De esta manera, los modos de producción fueron modificados respecto de la etapa anterior. Cada una de estas programaciones les permitió contar con diversos medios de difusión (avisos en las carteleras de los periódicos locales, panfletos, volantes y afiches). Así se tendieron nuevas articulaciones entre las 
prácticas del grupo y lo político, dejando atrás ese rechazo institucional provocado con el abandono de la Escuela de Teatro.

"A nosotros nos invitaron al Centro Cultural Recoleta a un ciclo que se llamó Nuevas Tendencias II. Allí, en ese espacio surgió hacer La Tirolesa", así recuerda Manuel Hermelo la participación en dicho festival. La Tirolesa tenía lugar al atardecer del día. El patio casi en oscuridad, de pronto era iluminado por un seguidor que dirigía la primera acción sobre las alturas. Dos de los performers descendían por una de las paredes del Patio de los tilos, cargando arneses, borceguíes, bermudas y una mochila con un chancho por la espalda (Primer elemento: Aire). Al llegar a la superficie, caían sobre unos piletones de barro. Lucha y juego dentro de estos contenedores de tierra húmeda (Segundo elemento: Tierra). Más tarde, las luces se dirigían hacia otros dos performers que descendían de uno de los puentes - que cruzaba el patio- y bajo una cortina de agua, que caía hasta el suelo, realizaban una coreografía suspendidos en el aire (Tercer elemento: Agua). El cuarto momento lo realizaban los últimos dos performers que danzaban en el aire, dentro de unos cuadriláteros de fuego construidos también como plataforma aérea (Cuarto elemento: Fuego). Todos los performers finalizaban cerca de la estructura metálica donde aparecía el fuego. Todos sobre las alturas. Mientras tanto, la musicalización del espectáculo era realizada en vivo con percusión de tanques y un ritmo envolvente. Los espectadores podían moverse libremente sobre la escena. Compartían el espacio escénico con los performers, viéndolos desde abajo.

\section{UNA POSTAL MONUMENTAL MUY PARTICULAR}

Algo de lo experimentado a nivel espacio aéreo en La Tirolesa fue retomado en diciembre de 1989 cuando obtuvieron la llave del monumento Obelisco, de sesenta metros de altura. Para esta ocasión, fue la propia Municipalidad la que se interesó por auspiciar y organizar la intervención urbana destinada para ser disfrutada en familia en vísperas navideñas. Los periódicos locales colaboraron con la difusión y publicaron notas, entrevistas y menciones que dieron visibilidad a la actividad, antes y después del evento. Sin duda, se trató de una postal inédita de la ciudad, porque a gran altura los cuerpos danzantes y acrobáticos se desplazaban por la ladera del monumento, configurando un suceso inolvidable de la ciudad para los treinta mil espectadores asistentes.

La Tirolesa/Obelisco consistió en la clara conquista del espacio público, en su máximo exponente. Haber llegado a la cima más alta de los espacios públicos como un evento programado para toda la familia trajo aparejadas otras 
formas de consumo del arte, en tanto producto cultural de una sociedad del espectáculo. ${ }^{23}$ En esta ocasión, el grupo se volvió parte de una política cultural pública apoyada y subvencionada no solo por la municipalidad sino también por tres empresas aseguradoras de riesgo de trabajo, consecuencia del riesgo que provocaba accionar en las alturas entre el monumento y una torre de andamio construida en la plaza aledaña. Artísticamente, LON otorgó cierta plasticidad a la rigidez del monumento, transitándolo y trepándolo en sus laderas, mediante arneses que permitieron desafiar la gravedad. Claramente esta performance adquirió otras resonancias poéticas respecto de la trayectoria grupal anterior, principalmente al ubicar el trabajo de los performers más alejado respecto del de los espectadores-ciudadanos, tensionados en una trama entre el espacio aéreo y el terrestre:

Esta relación airetierra le confiere a nuestro trabajo un carácter en que el funambulismo, basado sobre todo en técnicas de escalada de alta montaña, se constituye como sustento de las acciones que realizamos A diferencia de trabajos anteriores donde la médula escénica de accionar teatral era la fricción con el espectador, en la Tirolesa se busca la espectacularidad visual, diferenciando netamente, dos espacios, el aéreo (espacio de los modelos vivos o actores) y el terrestre (espacio de los espectadores) (Programa de mano). ${ }^{24}$

Sin duda, fue una imagen irrepetible del emblemático Obelisco, cuando la década avanzaba y el contexto nacional ya era diferente al de años precedentes. Hiperinflación económica, cambio de gobierno y otras tantas circunstancias sociopolíticas operantes y atravesadas, despegaron nuevas metáforas sobre la poética de LON. Así, el grupo logró llevar su arte hasta la cima de los espacios públicos propiamente dichos, el monumento más alto de la ciudad, siendo capaz de generar un teatro alejado de lo antropomórfico: sus performers podían reptar por la ladera del artefacto, danzar en el aire, colgarse con tirolesas y dominar el espacio aéreo. Entonces, la escena que antes se vivía directamente sobre la calle, en la primera etapa grupal, ahora se alejaba en una representación monumental. La postal efímera recreada, pero también los modos de mirar y evocar lo intangible latente -como usos de la memoria cultural y urbana- eran parte del asunto realizado. Así lo detallaban en un catálogo realizado luego de la performance:

La Tirolesa posee un tiempo de expectación, que quizás tenga que ver con la dimensionalidad, con lo atmosférico, con lo gravitacional. Los elementos que utilizamos: el cuerpo, el fuego, el agua, no responden a una

${ }^{23}$ Debord 2008 [1967].

${ }^{24}$ Programa de mano La Tirolesa/Obelisco (1989). 
alegoría preestablecida, sino a necesidades funcionales de nuestro trabajo. Por eso su utilización es gratuita, casual, y sólo se orienta a producir efectos, no una narrativa. Nos interesa lo que el ojo ve, lo que la oreja escucha, atendemos a la mirada sin explicaciones. La Tirolesa es una serie consecutiva de descensos y desplazamientos aéreos desde distintas alturas y lugares del espacio escénico..$^{25}$

Luego de esta intervención monumental, LON fue convocada a dos festivales internacionales, en Brasil y México, para repetir la experiencia en otras fachadas urbanas. Así, entre 1990 y 1991 realizó dos versiones for export de $L a$ Tirolesa/Obelisco, una en una fachada del Banco de Boston en el D.F. (México) y otra en una antigua estación ferroviaria en la ciudad de San Pablo (Brasil).

\section{El TEATRO OFICIAL Y LA POSIBILIDAD DE ACCIONAR PUERTAS ADENTRO}

La propuesta de una performance en un teatro oficial sorprendió a más de un seguidor del grupo. Ocurrió que a la vuelta de sus giras por Latinoamérica, el director de programación del Teatro Municipal General San Martín convocó a LON para realizar un espectáculo en una de sus salas. A pesar de las críticas que sobrevendrían con ello, LON apostó a la invitación y realizó el díptico de obras Almas examinadas, comprendido por Argumento y Almas.

La primera parte se llamó Argumento $^{26}$ y estaba ligada a experimentar y tematizar la fragilidad y la abstracción, basada en la exposición de la epidermis de los cuerpos de los performers o "modelos vivos". ${ }^{27}$ Había en ella una fuerte alusión a lo rudimentario y lo despojado que se desplegaba escénicamente a partir de dieciocho cuadros conformados por ocho performers desnudos. En estas imágenes, la iluminación -a partir de contrastes y sombras- resultó un factor fundamental para generar el patrón plástico visual de cada cuadro. La acción se iniciaba con el desplazamiento de los performers que solo vestían zapatillas negras, mientras algunas cámaras de video los buscaban por el espacio para registrarlos en unas pantallas de televisores que completaban la escena. La escasa escenografía se completaba con algunos libros. Desde esa desnudez se

${ }^{25}$ Programa de mano La Tirolesa/Obelisco (1989).

${ }^{26}$ Estrenada por separado el año anterior, en 1991, bajo el nombre de Argumentum Ornitologicum, dentro del marco de La Movida 5 y del Festival Nuevas Tendencias Escénicas organizado por el CELCIT en el Centro Cultural Recoleta. PACHECo 1992: 26.

27 Denominación que preferían usar, y sobre la cual venían trabajando desde $U O R C$, incluso explicándola en programas de mano anteriores. 
componían las imágenes/escenas o, en denominación de Carlos Pacheco, "esquemas corporales" ${ }^{\prime 28}$, al estar fragmentados por apagones recurrentes.

Estos cuerpos cargados de una gestualidad facial mínima, no diferenciados, no individualizados, se amontonaban, se abrazaban, se superponían, se separaban para crear las imágenes colectivas de una masa humana. Hablaban de la alienación, de la desesperación, de estar juntos o separados al borde del precipicio, de estar en una situación límite entre la vida y la muerte, hasta finalmente llegar a colocarse el ropaje cultural, como aquello que los limitaba y diferenciaba. ${ }^{29}$ Por su parte, Trastoy y Zayas de Lima, explicaban que:

Desde el comienzo los objetos se relacionaban dialógicamente con el cuerpo de los actores y los libros que permitían la lectura de un cuento de Borges se incendiaban al final del espectáculo entre las manos de los performers. Los cuerpos se exhibían escultóricamente reunidos, desnudos, patéticamente calzados en zapatillas deportivas, ocultando a veces sus genitales con terribles imágenes de castración. Finalmente los performers se vestían para poder realizar la lectura, marcando un pasaje de lo primitivo y lo elemental hacia lo intelectual y hacia los códigos sociales (¿de la prehistoria a la historia?). ${ }^{30}$

Mientras que la segunda parte, Almas -inspirada en Memorias de un neurópata de Sigmund Freud- planteaba otras líneas de acción: "un sueño con bomberos sueña en escena el sueño de un alma afiebrada sobre una manada". ${ }^{31}$ Allí LON se aproximó hacia la recreación de un mundo onírico e interior en el hombre, preguntándose si era posible que exista aquel que conoce lo desconocido. ${ }^{32}$ Para ello, mostraban el sueño surrealista de un joven bombero, como "una pesadilla, descripta en un estilo muy naif". ${ }^{33}$ Este personaje soñaba su propia persecución por parte de unos hombres uniformados que llegaban para someterlo e irrumpir su descanso y alterarlo.

La música -envolvente de sirenas, sonidos de disparos y armas de fuegoy la escenografía - un reloj gigante, una cama que hacía desaparecer personas, carpas en el suelo que se inflaban de repente, un robot parecido a un pequeño faro, velas que se encendían solas, entre otros elementos de utilería- generaron sobre el espacio escénico una atmósfera bastante enrarecida, a medida que el relato avanzaba. ${ }^{34}$ Según declaraban los propios integrantes de LON, en ese

28 PACHeCO 1992: 27.

${ }^{29}$ Mazas 1992b: 4.

30 Trastoy, Zayas de Lima 2006: 77-78.

31 Programa de Almas 1992.

32 Mazas 1992a: 4.

33 PACHeCo 1992: 27-28.

${ }^{34}$ El relato escénico también lograba articular reminiscencias estilísticas con imágenes relativas a los mundos creados por Lewis Carrol, Fritz Lang o Salvador Dalí, las cuales resultaron 
momento necesitaban que nuevas cosas los sedujeran, ya que durante mucho tiempo se habían definido por trabajar en espacios no teatrales. Según se señalaba en el programa de mano, tenían que demostrar que se podían adaptar y hacer teatro sea cual fuere el lugar destinado. ${ }^{35}$ Así estrenaron el 2 de junio de $1992^{36}$ y prolongaron el espectáculo por dieciocho únicas funciones:

Esta es la primera presentación en un escenario convencional del grupo La Organización Negra, cuya propuesta se caracteriza no solo por su singularidad respecto de cualquiera de las restantes experiencias escénicas que se presentan hoy en Buenos Aires, sino también por su personalísima utilización de un lenguaje poético convalidado tanto por la palabra cuanto por la gestualidad sobre las que se edifican estos espectáculos. ${ }^{37}$

Según se pudo relevar en varias críticas del espectáculo, para aquellos espectadores que ya conocían la poética de LON, esta segunda parte fue una gran decepción por concebir que el espíritu de La Negra se había perdido, y la principal causa era la utilización de un teatro convencional, delimitado entre platea y público. Sin embargo cabe aclarar que como, mencionábamos al comienzo de este trabajo, la exploración por lo novedoso y la ruptura con lo establecido, fueron modos de hacer constantes en LON. Por ello no era de sorprenderse que alojar sus prácticas en un espacio que había sido rechazado previamente, en este momento puntual de su trayectoria, pudiese ser considerado como posibilidad. Respecto de esto, nuestra hipótesis de lectura de esta etapa final sostiene que en estas instancias de producción, la estética grupal no pudo continuar siendo la misma o quedar aislada de las alteraciones que lo espacial proponía. Por lo que, necesariamente, el espectáculo en su conjunto no logró ser correspondido con aquellos objetivos iniciales planteados sobre el espacio urbano, ni con aquellas formas de politicidad expresadas. Sin embargo, no por ello dejó de ser novedoso para la trayectoria grupal.

visualmente muy atractivas.

${ }^{35}$ Nos preguntamos: ¿a quiénes tenían que demostrarle esa capacidad de adaptación? ¿A los agentes y críticos del campo (Bourdieu) teatral porteño que los había legitimado como nueva tendencia y que consideraban a su hacer como "teatro", al público que los seguía o al público habitué del teatro municipal?

${ }^{36}$ Ficha técnica: Almas examinadas (díptico a partir de Argumento y Almas). Grupo La Organización Negra. Guión y dirección: Manuel Hermelo. Intérpretes: Pichón Baldinu, Alfredo Visciglio, Diqui James, Enrique Calissano, Fabio D’Aquila, Daniel Conde, José Glauco, Domingo López y Gabo Correa (actor invitado). Textos: Dr. Elefant. Escenografía: Martín Etchegoyen y La Organización Negra. Diseño de producción: Liliana Ginitman. Asesoramiento sonoro: Willy Campins. Música: Gaby Kerpel. Sala Casacuberta del Teatro Municipal General San Martín, Buenos Aires.

37 Programa de Almas 1992. 
Respecto de la delimitación platea/escenario, fue el cambio estético más notorio que el grupo tuvo que afrontar al aceptar ser parte de una programación institucional. Este consistía en un anfiteatro semicircular con escenario elevado rodeado por una gradería capaz de albergar a unos quinientos sesenta y seis espectadores. ${ }^{38}$ Para los propios integrantes del grupo esto significó tener que pensar en una propuesta donde el público estuviera sentado durante toda la función, alejado de aquella proxemia perseguida durante ocho años y distanciado, por consiguiente, del escenario en cuestión. Es decir, ya no estarían corriendo o persiguiendo a los performers, ni mirando la escena arriba de sus cabezas por el espacio aéreo, ni sorprendidos de la acción inesperada durante el breve tiempo de un semáforo. Debían ser motivados a concurrir a dicha sala y tener que pagar una entrada por el espectáculo. En otras palabras, ser parte de un aparato teatral oficial implicó otros modos de producción ${ }^{39}$ muy diferentes de lo experimentado previamente. Incluso haber resignado la posibilidad de trabajar con el espacio aéreo, porque todas las escenas, de ambas partes, fueron realizadas sobre el escenario de la sala.

En cuanto a la utilización de la palabra hablada, se vislumbra la necesidad de contar una idea o una historia que les implicó apelar a la utilización de un contenido/recurso puesto sobre la escena. Esto se articula también con que en ambas partes hubo un texto origen, el de Borges y el Freud, sobre el cual trabajaron. Evidentemente, esto generó un contrapunto con los motores iniciales de "ganarle a las vidrieras", donde experimentar y transgredir formas cotidianas había sido clave. Si en ese momento la ciudad era la que les hacía preguntas como texto y como escenario a la vez, en Almas examinadas la ciudad ya no intervenía en el discurso de LON ni era su escenario, sino que permanecía alejada, como el simple exterior de la sala teatral donde tenían lugar ambas obras. Esto también implicó abordar una estructura narrativa con diferenciación de roles: observamos que al emplear una estructura narrativa, en la segunda parte, Almas, apareció la diferenciación de un rol singular, el del personaje protagónico/soñador. Esto no se había dado en las intervenciones previas, por lo general era todo el grupo, presentado como tal colectivamente, el que accionaba sin distinción de los roles asumidos - los cuales también eran intercambiables-. Es más, aun cuando hubiese habido algún Papa (como La procesión)

${ }^{38}$ Así se estructura la planta escénica de la sala Casacuberta de dicho teatro.

${ }^{39}$ Vale aclarar que además de los sueldos, el grupo tuvo a su disposición todos los servicios/ procedimientos propios del teatro en cuestión: diseño y realización de escenografía, iluminación, vestuario, maquillaje, programa de mano, departamento de prensa y difusión. Además de contar con acomodadores de sala, jefes técnicos, entre otros integrantes de todo el aparato funcional de la dependencia. 
o algunos roles más diferenciados (como también tuvo UORC) ellos no explicitaban quién era el performer a cargo.

Asimismo, no solo fue el empleo y armado de una estructura narrativa, sino los textos orígenes con los que se vincularon y explicitaron luego como hipotextos de ambas partes también fueron contrapuntos mantenidos respecto de la trayectoria anterior.

Y así como hubo cambios en la poética, también lograron plasmar continuidades. La palabra continuó presente en los programas de mano. A manera de carta de presentación, los programas de mano siempre les sirvieron de manifiestos, cual oportunidades para aclarar, expresar sus ideas, a modo de glosario o fixture de su trayectoria. De diferentes tamaños y extensión - algunos habían sido de varias páginas (como el de $U O R C$ ), otro una gigantografía (como el de la Tirolesa/Obelisco aludiendo a la escala monumental trabajada)- estos paratextos habían cargado con las palabras que la escena no presentaba o esclarecía. Aquí, en las dos partes de Almas examinadas, la palabra aparecía en ambos soportes: el escénico y el paratextual.

Y junto con la posibilidad de una sala oficial, apareció la posibilidad de llegar a nuevos públicos asistentes. Porque con este ingreso en el circuito teatral oficial LON obtuvo un nuevo público que accedió a ver su propuesta. Ciertamente, dicho ingreso hizo que el grupo concretara un mayor reconocimiento dentro del campo teatral de la ciudad y se legitimara con una gira internacional por varios festivales internacionales..$^{40}$ De todos modos, la mayor parte del público asistente habrían sido seguidores de LON que -sorprendidos con la propuesta- fueron autoconvocados para ver de qué se trataba, y que luego no aprobaron la propuesta.

$\mathrm{Y}$ en cuanto al desarrollo de un teatro de imagen, en esta ocasión oficial, LON continuó realizando un minucioso trabajo de sistema lumínico y sonoro capaz de seguir provocando y desconcertando al espectador, ahora más pasivo físicamente por estar sentado en una platea. Provocarlo desde la emergencia de cierta inquietud respecto de lo que estaba mirando fue un puntapié que quisieron retomar y aprovechar. Principalmente en la primera parte, Argumento, se observa que trabajaron la gestualidad corporal y la provocación a partir de la desnudez en las imágenes. Sin embargo, el impacto no fue tan contundente como se esperaba, por lo que dio como resultado algo poco aceptado y bastante criticado por el público en general.

En suma, es posible considerar que con Almas Examinadas LON afrontó el desafío de crear nuevas formas, las cuales, en gran medida, se mostraron contrarias a la propuesta teatral que cinco años antes los había colocado como

\footnotetext{
40 Vale mencionar el de Hamburgo -en agosto de 1992-, Nantes y Sevilla, en octubre de ese mismo año para cerrar junto a La Fura dels Baus en la Expo '92.
} 
vanguardistas de la escena local. Este ingreso en una sala convencional significó, entonces, el final de un ciclo. No apelaron a continuar en una misma línea de experimentación capaz de retomar aquellos elementos escénicos con los habían generado un reconocimiento y una estética teatral propia de índole provocadora, transgresora, urbana, fuertemente corporal y de impacto visual. Se arriesgaron a generar otra búsqueda: un espectáculo, en términos de representación, de realidad situada arriba de un escenario, alejada a la vida cotidiana y de la calle como escenario, empleando convenciones de recepción más tradicionales. En ese intento, el público no los acompañó porque los que los conocían esperaban otra cosa, la adrenalina y el impacto de sus performances anteriores. Tampoco se contentaron con estar sentados en una butaca, porque entendía que algo de lo realizado previamente se había perdido o diluido en este espectáculo.

Esta discusión estética no fue ajena a la conformación grupal, por lo que terminó con su disgregación. Luego fueron otros grupos los que sí retomaron aquellas líneas previamente trabajadas en ambas versiones de La Tirolesa como en $U O R C$, tales como el andinismo y teatro de acción en alturas, que lograron redefinir y profundizar un nuevo capítulo para esta vertiente teatral de acción e imágenes aérea.

\section{A modo de Conclusión}

De la intervención de espacios públicos periféricos, sorprendiendo a los transeúntes mediante el shock desprevenido de sus acciones urbanas iniciales, pasaron a tener espectadores teatrales acostumbrados a asistir a un teatro delimitado entre platea y escenario, y en donde la ciudad -como dijimos- ya no fue un elemento fundamental sobre el cual accionar. A partir de este contrapunto de sus comportamientos y formas estilísticas dado entre estos dos momentos de su trayectoria -inicios y desenlace grupal- nos resuenan los conceptos elaborados por Raymond Williams en torno a las diferentes tensiones y relaciones que involucra una producción o proceso cultural, entre formas y códigos emergentes, dominantes y residuales. ${ }^{41}$ Vale decir que los inicios de LON fueron claramente emergentes, como una nueva forma teatral que comenzaba a aparecer dentro del campo artístico de la ciudad en aquella transición democrática. Luego, con su consolidación y legitimación como grupo dentro de esta escena local, alcanzaron cierta forma o ubicación dominante que -gracias a diversos factores, entre ellos la crítica que los avaló y el público que lograron convocar, entre otros aspectos- les facilitó y vehiculizó la convocatoria a las diferentes

${ }^{41}$ WiLliams 1980 [1977]: 122. 
programaciones institucionales culturales anteriormente mencionadas. Más tarde, pareciera que su producción se volvió de algún modo residual, es decir, al no lograr permanecer en ese lugar central y diluyéndose como grupo, su línea estética fue continuada y retomada por el trabajo espacial y aéreo de otros grupos sucesores.

Resulta significativo observar que después de la disolución de LON, algunos de sus integrantes ${ }^{42}$ se reagruparon en otra formación artística y desde allí apelaron a profundizar la exploración del lenguaje teatral aéreo y espacial. Nos referimos a De La Guarda (en adelante DLG) que, desde 1992 logró reformular la propuesta teatral aérea, generando una continuidad estética respecto de los orígenes de LON. DLG alcanzó una legitimación dentro del campo durante toda la década siguiente y se mantuvo como forma dominante en esta especialidad teatral hasta, aproximadamente, el año 2005. Su reconocimiento como exponente de este tipo de teatro fue alcanzado tanto a nivel nacional ${ }^{43}$ como internacional. De esta manera, DLG logró convertirse en una marca o sello teatral, llevando sus espectáculos a diferentes continentes y cubriendo varios escenarios con elencos simultáneos. Así, no solo retomaron las técnicas aéreas sino que también apostaron nuevamente a la no delimitación entre platea y público, que se volvió un atractivo fundamental para lograr tal éxito mundial. Cabe señalar, sin embargo, que en esta refuncionalización de las técnicas no fueron retomados aquellos conflictos sociales y culturales o la violencia representada de las imágenes de LON, sino que DLG apostó a potenciar otro discurso, dirigido a expandir la capacidad lúdica de sus espectadores participantes. ${ }^{44}$ Tras la separación de DLG se crearon otras dos formaciones: Fuerza Bruta (en adelante FB) y Ojalá.$^{45}$ Ambos grupos se mantienen hasta la actualidad y están bajo la dirección de quienes fueron integrantes de LON.

En resumen, y para finalizar este recorrido de trayectoria y trayectorias derivadas, cabe señalar que FB también logró retomar algunos aspectos de las intervenciones urbanas plasmada por LON en sus inicios. Nos referimos a los festejos del Bicentenario Nacional (Buenos Aires, mayo de 2010), donde FB tuvo a su cargo la realización de un mega desfile artístico histórico de dieciocho carrozas alegóricas a la conmemoración de los 200 años de la Revolución de Mayo, que se trasladaron por diferentes calles del microcentro de Buenos Aires.

${ }^{42}$ Nos referimos principalmente a Pichón Baldinú y a Diqui James.

${ }^{43}$ A nivel nacional, cabe señalar que De La Guarda logró intervenir otro espacio abierto, público, como fue el velódromo de la ciudad e incluso llegó a construir espacios escénicos propicios para desarrollar su estética, como fue la sala Villa-villa del Centro Cultural Recoleta, el mismo edificio público donde años atrás habían realizado La Tirolesa (1988).

44 Trastoy, Zayas de Lima 2006: 80.

45 Pichón Baldinú y Diqui James se separan y arman estas dos formaciones, respectivamente. 
Estas carrozas lograron resemantizar un mismo espacio urbano intervenido por LON veintiún años antes, al pasar desfilando por los pies del emblemático monumento Obelisco. Dos contextos sociopolíticos distintos, dos maneras de intervenir performáticamente la misma porción de la ciudad.

Aun cuando aquellos inicios de LON hubieran sido consecuentes con ese estallido de participación ciudadana que marcó la transición democrática, y hubieran marcado la conquista del espacio público - aquel monumento en vísperas navideñas-, aun cuando la intervención de FB hubiese sido parte de los festejos oficiales conmemorativos en tiempos de globalización y saturación de publicidad dentro del espacio público, fue la misma ciudad la que albergó estas prácticas. Como escenario de acción, con dos décadas pasadas entre sí, la ciudad habilita reunir a la gente alrededor de una experiencia participativa, artística, ciudadana, política. Porque allí radica su capacidad de resemantizarse en diferentes momentos socio-políticos y de superponer su tiempo cotidiano con los extra-cotidianos planteados por las formas estéticas interventoras. Todo es parte de la conformación y fluctuación misma que permite la ciudad. De algún modo este recorrido por escenarios urbanos efímeros apuntó a dejar registro de estas prácticas que alguna vez sucedieron en Buenos Aires y que, constituyendo postales inéditas de la ciudad como escenario, se guardan en la memoria de su historia cultural.

\section{BibLIOGRAFÍA}

AA. VV. 1984 - AA. VV., "Revista/Plataforma política de La Negra”, 1984. Conservatorio Nacional de Arte Dramático.

Álvarez Ossorio 2007 - C. Álvarez Ossorio, El lugar del teatro, "ADE Teatro", n.116, 2007, pp. 59-62.

ANSALDI 2006 - W. Ansaldi, Juego de patriotas. Militares y políticos en el primer gobierno posdictadura en Bolivia, Brasil y Uruguay, en: A. Pucciarelli (coord.), Los años de Alfonsín ¿El poder de la democracia o la democracia del poder?, Buenos Aires 2006, pp. 23-61.

Blanco ET AL. 2001 - P. Blanco, J. Carrillo, J. Claramonte, M. Expósito, Modos de hacer. Arte crítico, esfera pública y acción directa, Salamanca 2001.

Bourdieu 1967 - P. Bourdieu, Campo intelectual y proyecto creador, en: J. Pouillon et al. Problemas del estructuralismo, México 1967, pp. 135-182. 
CARreira, VARgas 2009 - A. Carreira, A. Vargas, Teatro en la calle como performance invasora, en: O. Pellettieri (ed.), En torno a la convención y la novedad, Buenos Aires 2009, pp. 87-92.

Castro, Warley 1987 - A. Castro, J. Warley, Un teatro de posguerra, "Página 12, suplemento Culturas", 15 de noviembre de 1987, pp. 1-2.

Cruciani, Falletti 1992 - F. Cruciani, C. Falletti, El teatro de calle. Técnica y manejo del espacio, México 1992.

DACAL 2006 - E. Dacal, Teatro de la libertad: teatro callejero en la Argentina desde el movimiento grupal de los '80, Buenos Aires 2006.

Debord 2008 [1967] - G. Debord, Guy La sociedad del espectáculo, Buenos Aires 2008. [La Société du spectacle, 1967]

DubatTi 2006 - J. Dubatti (coord.), Teatro y producción de sentido político en la postdictadura: micropoéticas III, Buenos Aires 2006.

DuQue 2001 - F. Duque, Arte público y Espacio político, Madrid 2001.

González 2007 - M. L. González, Formas de explorar lo cotidiano: astillando la realidad, "Afuera. Estudios de crítica cultural", a.2, n.3, 2007, http://www.revistaafuera.com/NumAnteriores/pagina.php?seccion $=$ PraxisUrbana\&page $=03$.Praxis.urbana.gonzalez.htm\&idautor $=60$.

GonZÁLez 2008a - M. L. González, Entrevista a Manuel Hermelo, 10 de mayo de 2008.

González 2008b - M. L. González, Entrevista a Fernando Dopazo, 9 de octubre de 2008.

GonzÁLEz 2010 - M. L. González, Relatos artísticos latentes, "Afuera. Estudios de crítica cultural", a.5, n.9, 2010, http://www.revistaafuera. com/articulo.php?id=123\&nro $=9$.

GonzáLez 2011a - M. L. González, Teatro callejero y Performance urbana: dos maneras coyunturales de hacer Arte Público en democracia, en: Arte Público y Espacios Políticos: interacciones y fracturas en las ciudades latinoamericanas. II Seminario Internacional de Arte Público en Latinoamérica, Belo Horizonte 2011, pp. 453-462.

González 2011b - M. L. González, UORC de La Organización Negra: la enunciación de la experiencia según tres Autores, "Telón de fondo", n.14, 2011, http://www.telondefondo.org/numeros-anteriores/ numero14/articulo/363/uorc-de-la-organizacion-negra-la-enunciacion-de-la-experiencia-segun-tres-autores.html.

GonzÁLez 2015a - M. L. González, La Organización Negra. Performances urbanas entre la vanguardia y el Espectáculo, Buenos Aires 2015. 
GonzÁLEz 2015b - M. L. González, Escenarios urbanos: a propósito de La Organización Negra y su trayectoria centrípeta, "Apuntes de Teatro", n. 140, 2015, pp. 26-45.

Mas 2006 - P. Mas, La calle del teatro. Claves para entender el teatro de calle actual, Hiru 2006.

MAzas 1992a - L. Mazas, La negra regresa desde el alma, "Clarín, suplemento Espectáculos", 2 de junio de 1992, pp. 4-5.

MAZas 1992 b - L. Mazas, La verdad, entre enfoques ingenuos y delirantes, "Clarín, suplemento Espectáculos", 6 de junio de 1992, pp. 4,

Minelli 2006 - M. A. Minelli, Con el aura del margen (Cultura argentina en los '80/'90), Córdoba 2006.

Muzi 2001 - C. Muzi, Hijos del aire, "Clarín, Suplemento, Viva", 5 de agosto de 2001, p. 28.

Ospital 2009 - L. Ospital, Fue la hostia, "La Central", n.10, 2009, pp. 54-57.

PACHeCo 1992 - C. Pacheco, Riesgos examinados, "Teatro", 1992, pp. 26-28.

Pérez Royo 2008 - V. Pérez Royo, Danza en contexto. Una introducción, en: V. Pérez Royo (editor), ;A bailar a la calle! Danza contemporánea, espacio público y arquitectura, Salamanca 2008, pp. 13-65.

Programa de Almas 1992 - Programa Almas examinadas, de La Organización Negra, Teatro General San Martín, Centro de Documentación, Buenos Aires 1992.

SeOAne 2011 - A. Seoane, Festivales teatrales de Argentina, "Territorio teatral", n.7, 2011, http://territorioteatral.org.ar/html.2/articulos/n7_05. html.

Trastoy, Zayas de Lima 2006 - B. Trastoy, P. Zayas de Lima, Lenguajes escénicos, Buenos Aires 2006.

WiLliams 1980 [1977] - R. Williams, Marxismo y Literatura, trad. P. di Masso, Barcelona 1980. [Marxism and Literature, 1977] 


\section{Summary}

\section{Theater and post-dictatorship: La Organización Negra (The Black Organi- zation) and its ways of intervening in public space (performative key)}

This article investigates about two temporal space coordinates: Buenos Aires in the Postdictatorship. It dates from the Argentine democratic oncoming of December 1983, when that socio-cultural landscape of the city warned against changes and modifications respect to its previous period. Expanding into a multiplicity of artistic micropoetics, several theatre groups and collectives emerged in unconventional and peripheral areas of the city, attempting to reclaim the acceptance of stifled expression that existed during the previous years of the military dictatorship (1976-1983). The Organización Negra is one of these groups. In this article, we intend to address some aspects of its centripetal trajectory (1984-1992), which began in the margins of the theatrical field and culminated with the group's admission into a space belonging to the official theatrical circuit. At each stage, we intend to investigate the different modes of production, circulation and consumption of their practices. In other words, we observe the procedural aspects that -in pursuit of strengthening and generating their own poetics- were kept (or not) even when the spaces of action have been modified; and we analyze the intersections between art, politics, and the city that were established depending upon each historical moment. Thus, this study aims to record The Organización Negra's theatrical work, but also to establish its connections with contemporary poetics

\section{Streszczenie}

Teatr i postdyktatura: Organización Negra i jej sposoby interweniowania w przestrzeni publicznej (klucz performatywny)

Niniejszy artykuł omawia dwie współrzędne przestrzeni czasowej Buenos Aires w okresie postdyktatury. Wywodzi się od momentu nadejścia argentyńskiej demokracji w grudniu 1983 roku, kiedy to społeczno-kulturowy krajobraz miasta wykazywał nadejście zmian w stosunku do poprzedniego okresu. Rozwój wielu mikropoetyk artystycznych doprowadził do powstania w niekonwencjonalnych i peryferyjnych obszarach miasta kilku grup teatralnych i kolektywów próbujących odzyskać zdolność tendencyjnej ekspresji, która istniała w ostatnich latach dyktatury wojskowej (1976-1983). Jedną z tych grup jest Organización Negra. W artykule omówione zostały niektóre aspekty jej dośrodkowej trajektorii (1984-1992), która rozpoczęła się na marginesie działalności teatralnej i zakończyła się przyjęciem w ramy oficjalnych kręgów teatralnych. Zostały zaprezentowane różne metody tworzenia, obiegu i odbioru działalności tej organizacji na różnych etapach. Innymi słowy, działając zgodnie z aspektami 
proceduralnymi, które - z myślą o wzmocnieniu i generowaniu własnej poetyki - były zachowywane (lub nie) nawet wtedy, gdy obszary działania podlegały modyfikacjom. Przeanalizowano także punkty przecięcia sztuki, polityki i przestrzeni miasta, które zostały ukazane w zależności od konkretnej chwili historycznej. Artykuł ma na celu nie tylko opisanie działalności teatralnej Organización Negra, ale również ustalenie jej związków z poetyką współczesną.

thum. Katarzyna Szoblik 